\title{
Indoleamine 2,3-dioxygenase activity and clinical outcome following induction chemotherapy and concurrent chemoradiation in Stage III non-small cell lung cancer
}

\author{
Ben C. Creelan, ${ }^{1, *}$ Scott Antonia, ${ }^{2}$ Gerold Bepler, ${ }^{3}$ Timothy J. Garrett, ${ }^{4}$ George R. Simon ${ }^{5}$ and Hatem H. Soliman ${ }^{2}$ \\ 'University of South Florida; Tampa, FL USA; ${ }^{2}$ H. Lee Moffitt Cancer Center; Tampa, FL USA; ${ }^{3}$ Karmanos Cancer Institute; Wayne State University; Detroit, MI USA; \\ ${ }^{4}$ University of Florida; Gainesville, FL USA; ${ }^{5}$ MD Anderson Cancer Center; Houston, TX USA
}

Keywords: indoleamine 2,3 dioxygenase, innate immunity, kynurenine, non-small cell lung cancer, tryptophan

Abbreviations: AJCC, American joint committee on cancer; AUC, area under the curve; BIN1, bridging integrator 1;

CI, confidence interval; CT, computed tomography; CTLA-4, cytotoxic T-lymphocyte antigen 4;

D-1MT, 1-methyl-D-tryptophan; ECOG, Eastern Cooperative Oncology Group; GCN-2, general control nonrepressed 2;

HPLC, high performance liquid chromatography; HR, hazard ratio; IDO, indoleamine 2,3 dioxygenase; IFN, interferon;

IHC, immunohistochemistry; ILT, immunoglobulin-like transcript; IPMN, intraductal papillary mucinous neoplasm;

Kyn, kynurenine; MS, mass spectrometry; mTOR, mammalian target of rapamycin; NCT, national clinical trial;

NSCLC, non-small cell lung cancer; OS, overall survival; PET, positron emission tomography; PFS, progression-free survival; PKC $\Theta$, protein kinase $\mathrm{C} \Theta$; RECIST, response evaluation criteria in solid tumors; STAT1, signal transducer and activator of transcription 1; TGF, transforming growth factor; TIL, tumor-infiltrating lymphocyte; Trp, tryptophan

\begin{abstract}
Indoleamine 2,3-dioxygenase (IDO) has recently been proposed to account for tumor-induced immunosuppression by influencing the conversion of tryptophan (Trp) into kynurenine (Kyn). The objective of our study was to correlate IDO activity with disease outcome in non-small cell lung cancer (NSCLC) patients treated with multimodal combination therapy. In a single-arm Phase II trial involving induction gemcitabine and carboplatin followed by concurrent paclitaxel, carboplatin and 74 Gy thoracic radiation in Stage III NSCLC patients, plasma was drawn at baseline, post-induction, and post-concurrent therapy. The mean plasma Kyn/Trp ratio was used as a surrogate indicator of IDO activity. The 33 participants were distributed as follows: 15 females, 18 males; median age $=62$; median overall survival (OS) $=22.4(95 \%$ Cl 19.3-25.1) months; median progression-free survival (PFS) $=11.5(95 \% \mathrm{Cl} 6.7-16.3)$ months. The mean $\mathrm{Kyn} / \mathrm{Trp}$ ratio at baseline $(4.5 \pm 2.8)$ was higher than that of healthy controls $(2.9 \pm 1.9, \mathrm{p}=0.03)$ and increased after induction therapy (5.2 $\pm 3.2, p=0.08$ ) and chemoradiation $(5.8 \pm 3.9, p=0.01)$. The post-treatment $K y n / T r p$ ratio and radiologic responses were not significantly associated at any time point. No significant correlation was found between baseline Kyn/Trp ratios and OS ( $\mathrm{HR}=1.1,95 \% \mathrm{Cl} 0.45-2.5$ ) or PFS ( $\mathrm{HR}=0.74,95 \% \mathrm{Cl} 0.30-1.82)$. A post-induction chemotherapy increase in IDO activity portended worse OS ( $\mathrm{HR}=0.43,95 \% \mathrm{Cl} 0.19-0.95, \mathrm{p}=0.037)$ and PFS ( $\mathrm{HR}=0.47,95 \% \mathrm{Cl} 0.22-1.0, \mathrm{p}=0.055)$. This observed increase in IDO transcription may be a means for tumors to evade immunosurveillance.
\end{abstract}

\section{Introduction}

Indoleamine 2,3-dioxygenase (IDO) is a cytosolic protein that catalyzes the rate-limiting step of human tryptophan (Trp) metabolism. Trp depletion induces effector $T$ cells to undergo a $G_{1}$ cell cycle arrest ${ }^{1}$ and triggers an integrated stress response pathway that involves general control nonrepressed $2(\mathrm{GCN} 2)$ signaling and eukaryotic initiation factor $2 \alpha$ (eIF2 $\alpha$ ) phosphorylation. ${ }^{2,3}$ IDO also causes systemic anergy by inducing naive
$\mathrm{T}$ cells to differentiate into $\mathrm{CD} 4{ }^{+} \mathrm{CD} 25^{+} \mathrm{FOXP} 3{ }^{+}$regulatory T cells. ${ }^{4}$ Dendritic cells respond to low Trp levels by upregulating inhibitory factors such as immunoglobulin-like transcript 3 (ILT3), ILT4 and transforming growth factor $\beta 1$ (TGF- $\beta 1$ ), thus becoming immunosuppressive. ${ }^{5}$ Moreover, Trp metabolites such as kynurenine (Kyn), quinolinic acid, and picolinic acid exert cytotoxic effects on $\mathrm{CD}^{+}$tumor-infiltrating lymphocytes (TILs) and $\mathrm{CD}^{+} \mathrm{T}_{\mathrm{H}} 1$ cells. ${ }^{6,7}$ The IDO-mediated deprivation of $\operatorname{Trp}$ also inhibits the immunomodulatory kinases mammalian target 


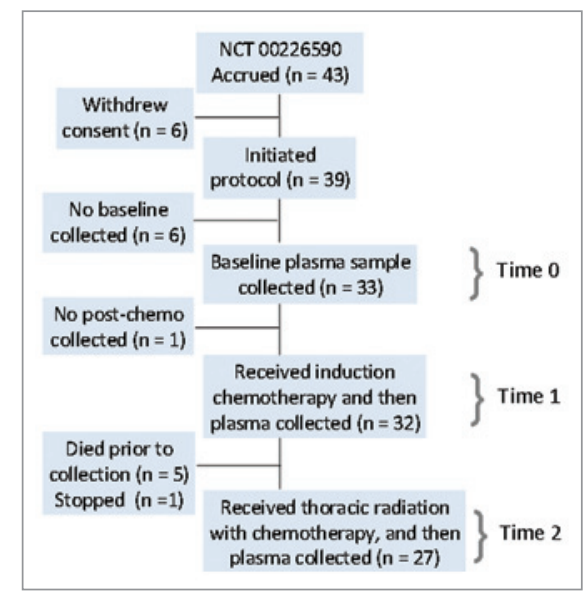

Figure 1. Trial flow diagram. Induction chemotherapy: gemcitabine and carboplatin. Thoracic radiation: 74 Gy conformal. Concurrent chemotherapy: paclitaxel and carboplatin.

of rapamycin (mTOR) and protein kinase $\mathrm{C} \Theta(\mathrm{PKC} \Theta)$, thereby inhibiting autophagy. ${ }^{8}$ In fact, IDO is overexpressed by many human cancers ${ }^{9}$ and may serve as an escape mechanism from host immunity. ${ }^{10}$ For example, in humans and animals, the induction of IDO limits the immune response to dendritic cell-based anticancer vaccines. ${ }^{11,12}$ Cancer cells bearing mutations in the oncosuppressor gene BIN1 are stimulated by interferon $\gamma($ IFN $\gamma)$ to overexpress IDO, leading to increased intracellular levels of signal transducer and activator of transcription 1 (STAT1) and nuclear factor $\kappa \mathrm{B}(\mathrm{NF} \kappa \mathrm{B}){ }^{13}$ Thus, IDO may be an important stimulator of immune tolerance in human cancer.

Non-small cell lung cancer (NSCLC) is an aggressive epithelial malignancy that often overexpresses the mRNA coding for IDO.$^{14}$ NSCLC has an annual incidence of 1.61 million people worldwide, ${ }^{15,16}$ and 83 percent of NSCLC patients will eventually die of their cancer. ${ }^{16}$ Locoregionally-advanced NSCLC comprises more than one-third of cases at presentation and is classified as Stage III. ${ }^{17}$ Over three quarters of Stage III NSCLC patients are technically or medically inoperable. ${ }^{18}$ Chemotherapy and concurrent radiation is the standard therapy for inoperable Stage III NSCLC, but the five year overall survival (OS) remains poor, that is, $20 \%$ and $8 \%$ for IIIA and IIIB disease, respectively. ${ }^{19}$ Such an aggressive malignant phenotype has been hypothesized to stem from an innate resistance of NSCLC to chemotherapy ${ }^{20,21}$ and to its ability to evade immunosurveillance. ${ }^{22,23}$ However, the role of IDO in mediating immune tolerance in NSCLC is unclear.

Trp catabolism in lung cancer patients is associated with advanced disease stage. ${ }^{24,25}$ This said, how IDO activity changes

Table 1. Demographics and baseline measurements

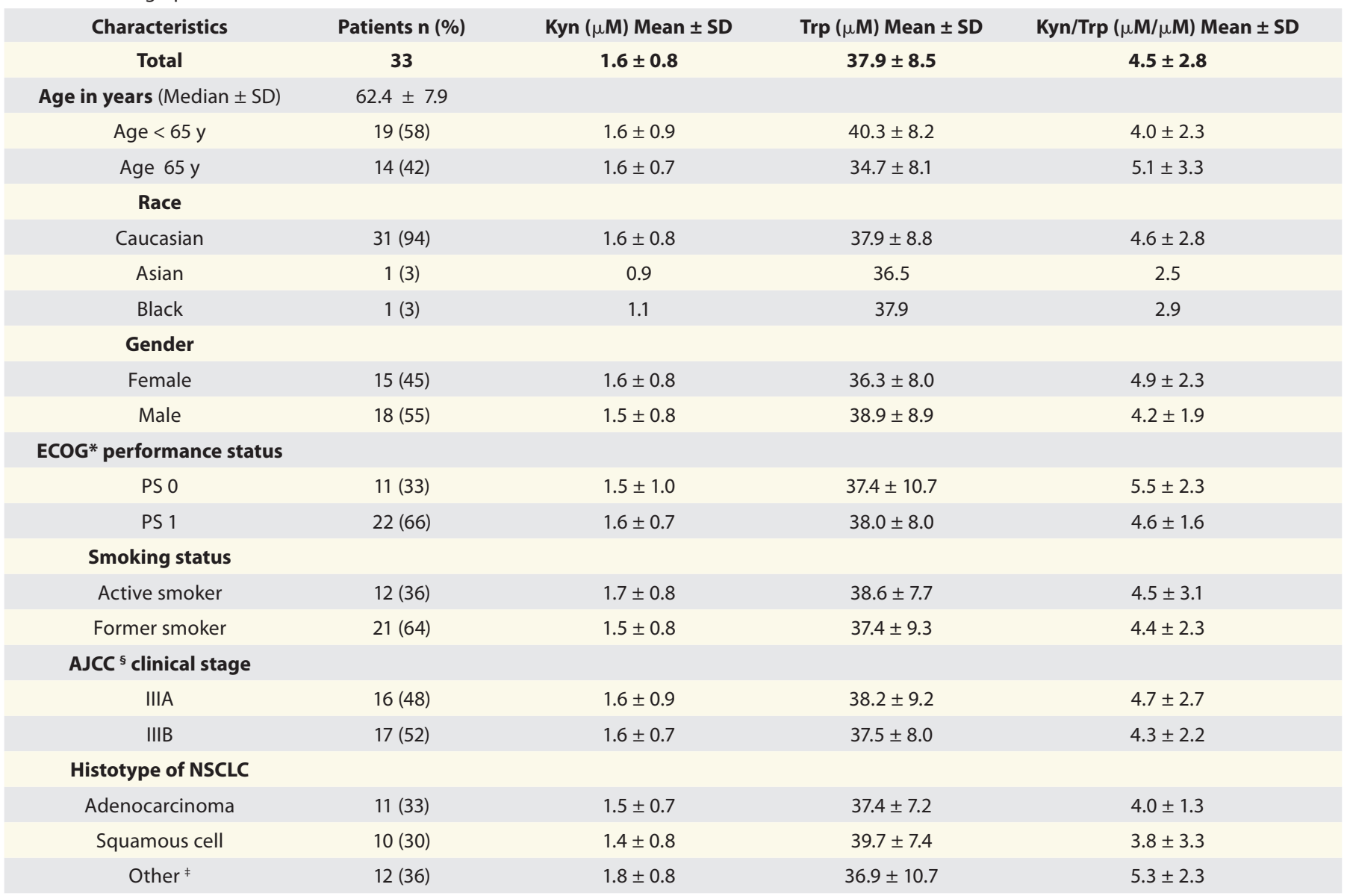

*Eastern Cooperative Oncology Group. ${ }^{\S}$ American Joint Committee on Cancer. "Includes bronchoalveolar, large cell and "not otherwise specified." No statistically significant mean difference was detected for any comparison of the groups presented ( $p<0.05$, Wilcoxon rank-sum test). 
after chemotherapy or radiation in NSCLC patients is unclear. The abrogation of BIN1 causes IDO overexpression and promotes NSCLC in animals. ${ }^{26}$ NSCLC-infiltrating lymphocytes are often anergic and hypoproliferative, ${ }^{27}$ and the overexpression of IDO in the NSCLC peritumoral stroma is associated with poor prognosis. ${ }^{28}$ Based on the these observations, we hypothesized that IDO activity may increase in Stage III NSCLC patients undergoing conventional multimodal therapy. Since Kyn is the primary metabolite of Trp metabolism, the plasma Kyn/Trp ratio has been used as a surrogate indicator of IDO activity. ${ }^{29,30}$ Our objective was to prospectively correlate serial changes in IDO activity, as measured by the plasma Kyn/Trp ratio, with radiologic response and survival in NSCLC patients treated with multimodal therapy.

\section{Results}

Forty-three participants were enrolled from December 2003 to February 2006. Of 39 participants initiated on treatment, 33 had plasma drawn at Time 0 evaluable for mass spectrometry (Fig. 1). We observed no trends between baseline plasma metabolites and demographic features such as age, race, gender, and performance status (Table 1). Moreover, we observed no correlations between baseline plasma markers and tumor characteristics such as histology or clinical stage. However, these correlative studies were limited by a relatively low statistical power. To assess the presence of outliers, we used a formal outlier test, the extreme studentized deviate (ESD) method with $\mathrm{p}<0.05$, which identified one outlier at time $0(14.5$ with $\mathrm{z}=3.6)$ and no outliers at Time 1 and Time 2. To further assess the influence of outliers, we examined the clinicopathologic features of the six participants displaying the highest Kyn/Trp ratio at Time 0 and Time 1 compared with the rest the cohort. No statistically significant differences in age, survival, tumor burden, chemotherapy response, white blood count and serum albumin was observed.

Compared with a sample of 24 healthy controls $(2.9 \pm 1.9)$, participants had higher mean Kyn/Trp ratio at baseline $(4.5 \pm 2.8$, $\mathrm{p}=0.03$ ) (Fig. 2). Mean plasma Kyn/Trp ratios increased after induction chemotherapy (Time 0 to Time $1,5.2 \pm 3.2, p=0.08$ ), and after concurrent definitive chemoradiation (Time 1 to Time 2, $5.8 \pm 3.9, \mathrm{p}=0.01)$. No correlation was observed between baseline plasma Kyn/Trp ratios and primary tumor cross-sectional area $(r=0.10,95 \%$ CI $-0.27-0.43)$ or total crosssectional area of all target lesions on CT (CT) $(r=0.02,95 \%$ CI -0.33-0.37) (Fig. 3A). Likewise, no appreciable correlation was observed between changes in plasma Kyn/Trp ratios from Time 0 to Time $1\left(\Delta \mathrm{IDO}_{1}\right)$ and changes in primary tumor crosssectional area $(r=-0.25,95 \% \mathrm{CI}-0.56-0.12)$ or changes in total cross-sectional area of all target lesions on CT $(r=-0.17,95 \%$ CI -0.50-0.20) (Fig. 3B).

After induction chemotherapy, we observed one complete response, 11 partial responses and 21 patients with stable disease. Using response evaluation criteria in solid tumors (RECIST), a non-statistically significant association was observed between improved radiologic responses and plasma Kyn/Trp ratios at Time 1, with $\mathrm{p}=0.34$ (Fig. 4A). A similar non-significant trend was observed between radiologic responses and plasma Kyn/Trp

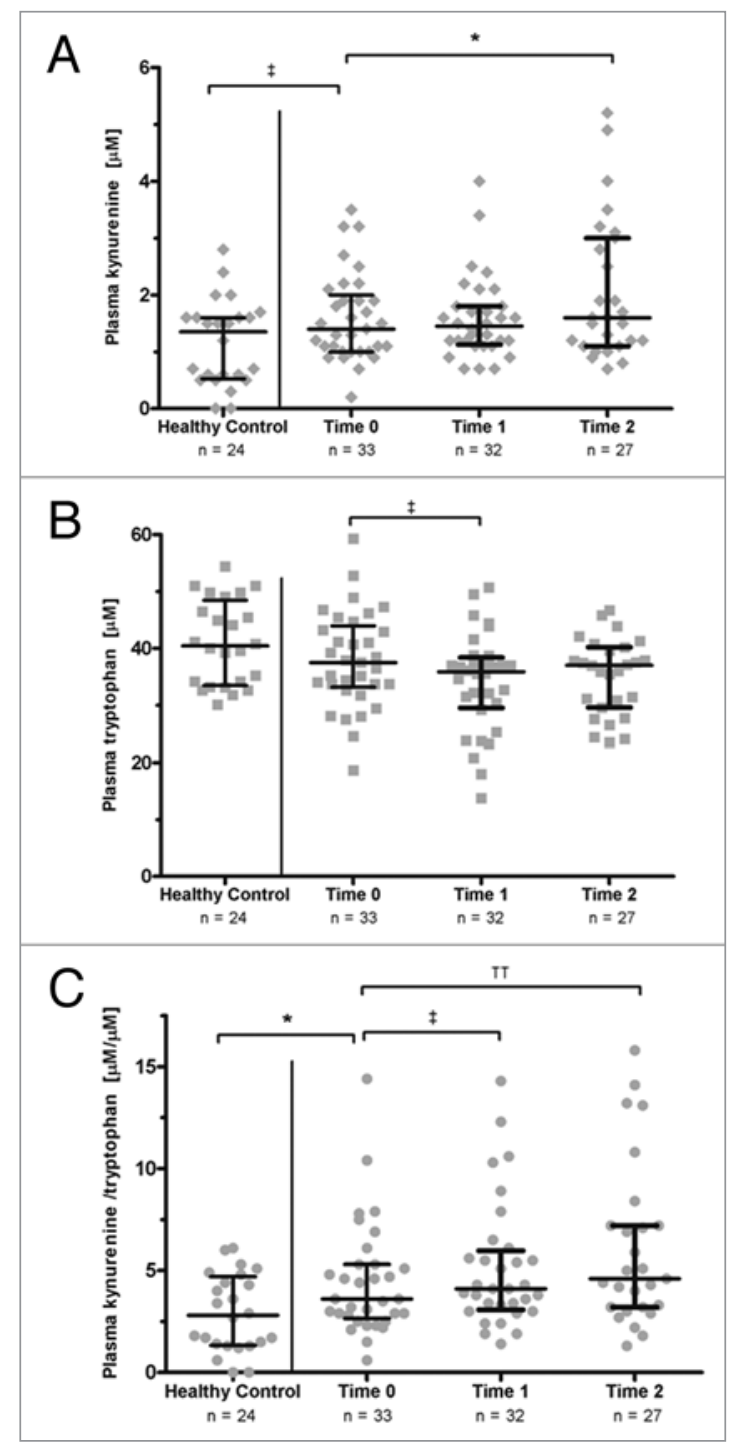

Figure 2. Plasma metabolites in Stage III non-small cell lung cancer patients. (A) Plasma kynurenine (Kyn) concentration. (B) Plasma tryptophan (Trp) concentration. (C) Plasma Kyn/Trp ratios, a surrogate for indoleamine 2,3 dioxygenase (IDO) activity. Plasma IDO activity was higher in non-small cell lung cancer (NSCLC) patients at baseline (Time 0 ) than in healthy individuals. Plasma IDO activity increased after induction carboplatin/gemcitabine (Time 1) and after concurrent carboplatin/paclitaxel with thoracic radiation (Time 2). Bars: Median with interquartile range. For healthy individuals vs. Time 0: Wilcoxon rank-sum test. For Time 0 vs. Time 1 and Time 1 vs. Time 2: Wilcoxon signed-rank test. ${ }^{\ddagger} p<0.10 ;{ }^{*} p<0.05 ;{ }^{\dagger+} p<0.01$.

ratios at Time 2, with $\mathrm{p}=0.19$ (Fig. 4B). To index the shift in IDO activity after chemotherapy, the differences in Kyn/Trp ratios between Time 0 and Time $1\left(\Delta \mathrm{IDO}_{1}\right)$ and between Time 1 and Time $2\left(\Delta \mathrm{IDO}_{2}\right)$ were calculated. Participants were subdivided into two groups based on the median $\Delta$ IDO value. Using RECIST to define the percentage of response, a non-significant trend was observed between radiologic responses at Time 1 and $\Delta \mathrm{IDO}_{1}$ (Fig. 5).

Median OS was 22.4 mo (95\% CI 19.3-25.1) and median progression-free survival (PFS) 11.5 mo (95\% CI 6.7-16.3) (Table 2). 


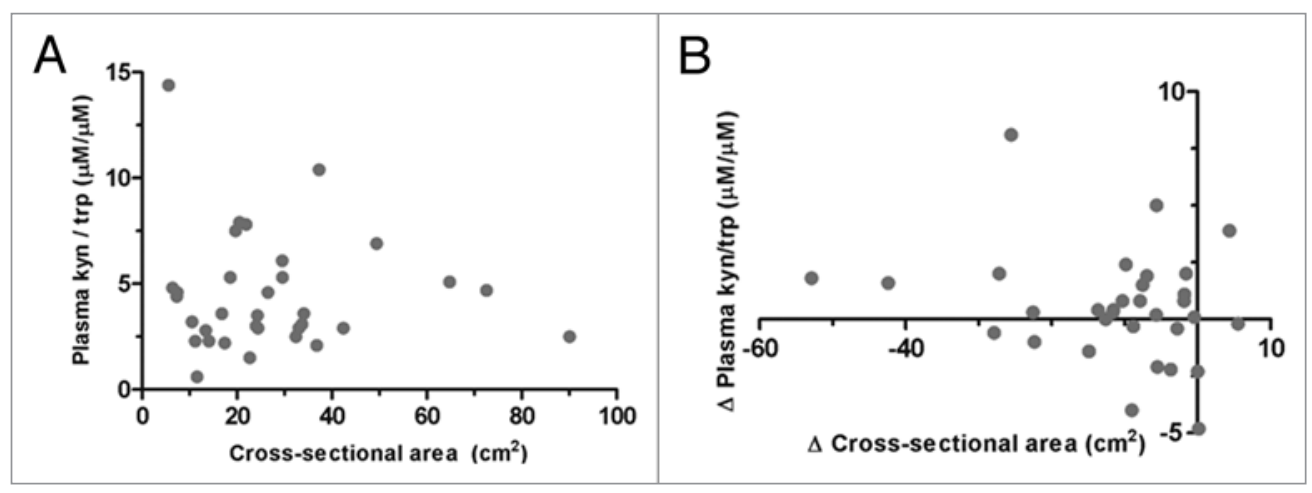

Figure 3. Correlation between tumor burden and indoleamine 2,3 dioxygenase activity. (A) Correlation between cross-sectional tumor burden and plasma kynurenine/tryptophan (Kyn/Trp) ratio. $\mathrm{n}=33, r=0.02(95 \% \mathrm{Cl}-0.33-0.37)$. (B) Correlation between changes in cross-sectional tumor burden and changes in plasma Kyn/Trp ratios after induction carboplatin/gemcitabine (Time $1-$ Time 0 ). $n=32, r=-0.17$ ( $95 \% \mathrm{Cl}-0.50-0.20$ ). Total burden represents the sum of cross-sectional areas for primary tumor and all target lymph nodes. Cross-sectional area represents the product of the longest tumor diameter and its perpendicular axis. $r=$ Spearman's rank correlation coefficient.

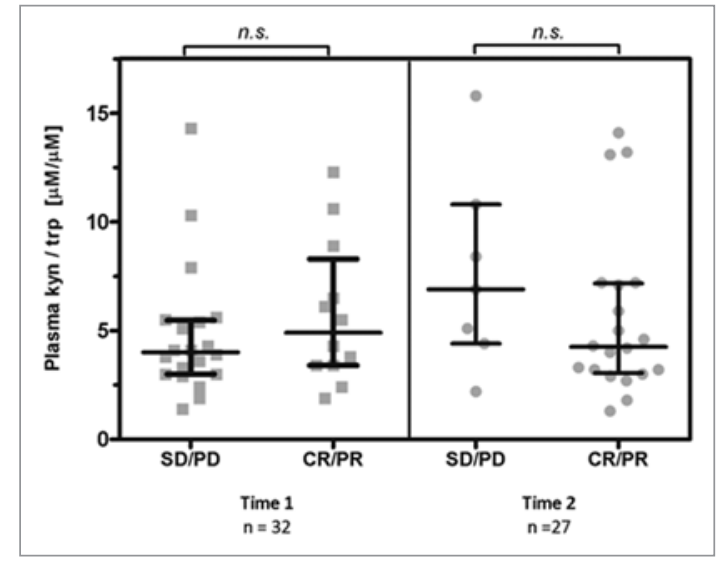

Figure 4. Radiologic response and plasma kynurenine/tryptophan ratio after induction therapy (Time 1) and after concurrent carboplatin/ paclitaxel therapy coupled to thoracic radiation (Time 2). Bars: median, interquartile range. $n . S .=$ non significant (Wilcoxon rank-sum). $C R$, complete response; $\mathrm{PD}$, progressive disease; $\mathrm{PR}$, partial response; $\mathrm{SD}$, stable disease.

Baseline Kyn/Trp ratios were not significantly associated with OS $(\mathrm{HR}=0.88,95 \% \mathrm{CI} 0.41-1.35)$. After induction chemotherapy at Time 1, patients with high $\Delta \mathrm{IDO}_{1}$ had worse OS $(\mathrm{p}=0.037)$ and a trend toward worse PFS ( $\mathrm{p}=0.055)$ as compared with individuals with low $\Delta \mathrm{IDO}_{1}$ (Fig. 6). However, no association was found after chemoradiation between $\Delta \mathrm{IDO}_{2}$ and $\mathrm{OS}(\mathrm{HR}=1.1$, $95 \%$ CI $0.45-2.5)$ or PFS (HR $=0.74,95 \%$ CI $0.30-1.82)$.

\section{Discussion}

To our knowledge, this is the first report to serially explore changes in plasma IDO activity during the treatment of Stage III NSCLC patients, as measured by Kyn/Trp ratios. We found that IDO activity was higher in cancer patients than in healthy individuals, consistent with previous observations in lung can$\mathrm{cer}^{24,25,31}$ bladder cancer, hepatocellular carcinoma, renal cell
Table 2. Summary of results

\begin{tabular}{|cccc|}
\hline Characteristics & Time $\mathbf{0}$ & Time $\mathbf{1}$ & Time 2 \\
\hline $\mathbf{N}$ & $\mathbf{3 3}$ & $\mathbf{3 2}$ & $\mathbf{2 7}$ \\
\hline Analytes $($ mean $\pm \mathrm{SD})$ & & & \\
\hline Kyn $(\mu \mathrm{M})$ & $1.59 \pm 0.77$ & $1.58 \pm 0.73$ & $2.05 \pm 1.25$ \\
\hline $\operatorname{Trp}(\mu \mathrm{M})$ & $37.9 \pm 8.5$ & $34.1 \pm 8.7$ & $35.2 \pm 6.7$ \\
\hline Kyn/Trp $(\mu \mathrm{M} / \mu \mathrm{M})$ & $4.5 \pm 2.8$ & $5.15 \pm 3.12$ & $6.11 \pm 4.02$ \\
\hline Radiology & & & \\
\hline Primary tumor area $\left(\mathrm{cm}^{2}\right)$ & $18.7 \pm 17.9$ & $11.0 \pm 10.4$ & $5.5 \pm 4.7$ \\
\hline Total tumor area $\left(\mathrm{cm}^{2}\right)$ & $27.6 \pm 19.2$ & $16.1 \pm 12.0$ & $7.4 \pm 5.5$ \\
\hline Survival & Median & $\mathbf{9 5 \%} \mathrm{Cl}$ & Events \\
\hline PFS $(\mathrm{mo})$ & 11.5 & $(6.7-16.3)$ & $29 / 33$ \\
\hline OS $(\mathrm{mo})$ & 22.2 & $(19.2-25.1)$ & $27 / 33$ \\
\hline
\end{tabular}

PFS, progression-free survival; $\mathrm{OS}$, overall survival; $\mathrm{Cl}$, confidence interval; SD, standard deviation; Mo, months.

carcinoma, melanoma, ${ }^{32}$ colorectal carcinoma, ${ }^{33}$ esophageal cancer, ${ }^{34,35}$ thyroid carcinoma, ${ }^{36}$ acute myelogenous leukemia, ${ }^{37}$ breast cancer ${ }^{38}$ and gynecologic cancer ${ }^{29}$ patients. This observation lends credence to the hypothesis that cancer cells may stimulate dendritic cells to express IDO or may directly overexpress the enzyme. Indeed, NSCLCs exhibit high Trp metabolism as monitored by $\alpha$-methyl-tryptophan positron emission tomography (PET) imaging as compared with normal tissues. ${ }^{39}$ We could not observe a strong correlation between baseline tumor sizes and $\mathrm{Kyn} / \mathrm{Trp}$ ratios, or a strong correlation between changes in tumor size and changes in Kyn/Trp ratios. This suggests that Kyn/Trp ratios are unlikely to be determined by the tumor burden alone.

Consistent with previous observations in NSCLC patients, ${ }^{24}$ we did not find a correlation between baseline IDO activity and survival. Several authors have examined the relationship between IDO activity and survival in other cancers (Table 3). Of interest, studies based on the immunohistochemical detection of IDO more often reported an unfavorable role for IDO than studies based on the detection of IDO mRNA levels (16:1 vs 1:6, 


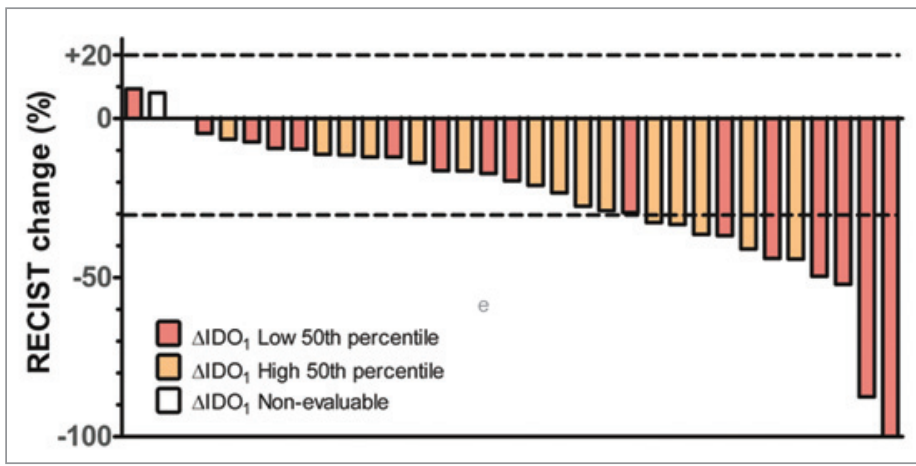

Figure 5. Waterfall plot of response after induction chemotherapy. Participants with reduced surges in indoleamine 2,3 dioxygenase (IDO) activity after induction chemotherapy $\left(\Delta \mathrm{IDO} \mathrm{O}_{1}\right)$ had non-significant trend toward improved radiologic responses. The median difference in the kynurenine/ tryptophan (Kyn/Trp) ratio was taken as pre-specified cut-point. Evaluable patients, $\mathrm{n}=32$; non-evaluable patients, $\mathrm{n}=1$.

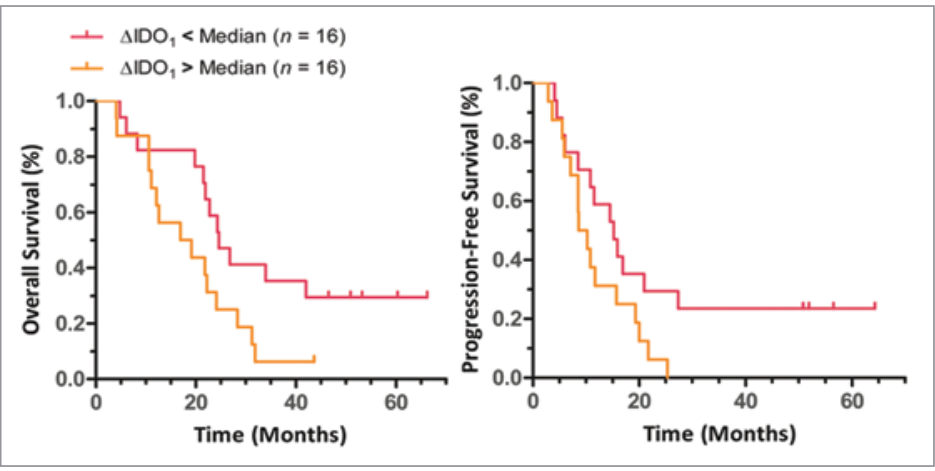

Figure 6. Relationship between changes in indoleamine 2,3 dioxygenase activity and non-small cell lung cancer patients survival. Participants with a consistent increase in indoleamine 2,3 dioxygenase (IDO) activity from baseline (Time 0 ) to induction chemotherapy (Time 1) had shorter overall survival (OS) and a trend toward shortened progression-free survival (PFS). Median $\mathrm{OS}=24.6$ vs. $18.0 \mathrm{mo}, \mathrm{HR}=0.43(95 \% \mathrm{Cl} 0.19-0.95),{ }^{*} \mathrm{p}=0.037$ (Log-rank test) Median PFS: 15.2 vs. $9.4 \mathrm{mo}, \mathrm{HR}=0.47(95 \% \mathrm{Cl} 0.22-1.02)$, ${ }^{*} \mathrm{p}=0.055$ (Log-rank test). Median difference in kynurenine/tryptophan (Kyn/Trp) $\left(\Delta I D O_{1}\right)$ was taken as pre-specified cut-point.

Fischer's exact $\mathrm{p}=0.0003)$. This difference may reflect a posttranscriptional regulation of IDO. Our study also examined the relationship between changes in IDO activity and disease outcome. Our results suggest that a high increase in IDO activity after chemotherapy is associated with a higher risk of mortality. A possible explanation for our findings is that the expression of IDO by tumor cells may mediate-at least in part-resistance to chemotherapy. ${ }^{40}$ Along these lines, it has recently been reported that a subset of NSCLC patients with favorable radiologic responses after chemotherapy exhibit a significant decrease in IDO activity within monocytes as compared with baseline conditions. ${ }^{41}$ Tumors may generate a hostile microenvironment that impedes host antitumor immune response. Interestingly, no changes in the expression of IDO by tumor cells was observed in melanoma biopsies at baseline and during regression in response to tremelimumab treatment ${ }^{42}$ suggesting that IDO activity may not be influenced by cytotoxic T-lymphocyte antigen 4 (CTLA-4) inhibition.

Several aspects of our report necessitate a more detailed investigation before firm conclusions can be drawn. Due to a small sample size, our trial was statistically underpowered to detect any significant association between Kyn/Trp ratios and demographic characteristics. Likewise, our patient sample was too small to establish a stepwise dose-effect relationship between IDO activity and clinical outcome. Next, tissues were not available for the immunohistochemical detection of IDO, so we used plasma Kyn/Trp ratios as a convenient surrogate marker for IDO activity. Other studies have used plasma $\mathrm{Kyn} / \mathrm{Trp}$ ratios as an indirect measure for IDO activity (Table 3) and these correlate well with immunohistochemical data. ${ }^{43}$ However, plasma Kyn/Trp ratios are not a direct measure of IDO activity. In particular, other Trp catabolizing enzymes, including tryptophan 2,3-dioxygenase and the IDO splice variant known as IDO2 contribute to Kyn production as well. Moreover, our study did not mandate uniform timing for blood draws. Since plasma Trp levels may vary by as much as $20 \%$ in the same subject depending on the distance of the last meal and the diurnal cycle, ${ }^{44}$ we acknowledge this as a potential confounder. Nonetheless, plasma Kyn has only minor diurnal variation, ${ }^{43}$ and the changes that we observed in Kyn/Trp ratios appeared predominantly attributable to Kyn (Fig. 2). Another drawback of the present study is that correlative immunologic markers, such as FOXP3 expression, CD3 activity, and IFN production were not measured. Additional markers may help to substantiate the putative role of IDO in this patient population. Moreover, conclusions cannot be drawn about the effect of individual chemotherapy agents, which are known to have specific immunomodulatory properties. ${ }^{45,46}$ Finally, our calculations were performed without multiple comparison rules. ${ }^{47}$ Thus, the possibility exists that the observed associations could stem from family-wise errors. In view of all these limitations, our results should be strictly viewed as exploratory.

In summary, our findings may serve as a rationale for larger studies correlating changes in the Kyn/Trp ratio with clinical parameters during standard multimodal therapy against NSCLC. As IDO may contribute to the resistance of NSCLC to therapy, this clinical setting may be a fertile area for the investigation of the antineoplastic effects of IDO inhibitors, such as1-methyl- $D$-tryptophan (D-1MT).$^{48}$

\section{Materials and Methods}

Patients. The design of the clinical trial has been previously described. ${ }^{49}$ Briefly, our single-arm trial used induction gemcitabine $\left(1 \mathrm{~g} / \mathrm{m}^{2}\right)$ on day 1 and day 8 and carboplatin $(A U C=5)$ on day 1 given at 4 -week intervals for two cycles. This was followed by weekly carboplatin $(\mathrm{AUC}=2)$ and paclitaxel $\left(50 \mathrm{mg} / \mathrm{m}^{2}\right)$ with concurrent conformal radiation (dose $=74 \mathrm{~Gy} \pm 5 \%$ ) administered over 40 daily fractions. Plasma was collected at baseline (Time 0 ), after induction at week 9 (Time 1), and after 
Table 3. Select studies of indoleamine 2,3 dioxygenase IDO in human cancers

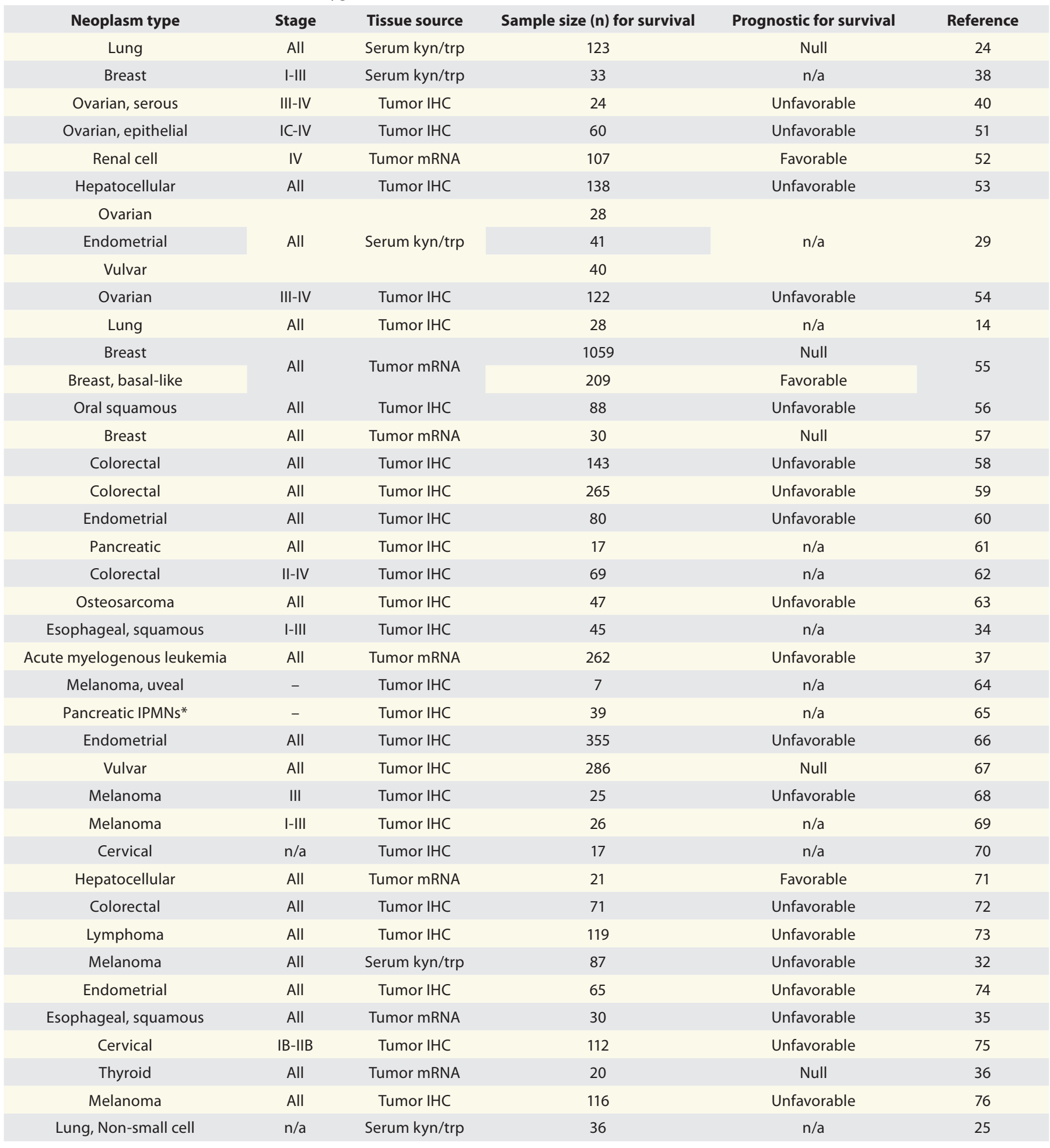

Favorable, improved survival with higher IDO; unfavorable, worse survival with higher IDO; null, no difference observed; n/a, not tested; IHC, Immunohistochemistry. *Intraductal papillary mucinous neoplasm.

concurrent therapy at week 25-26 (Time 2). All participants enrolled had previously untreated clinical Stage IIIA or "dry" IIIB NSCLC, as determined by American Joint Committee on Cancer (AJCC) criteria v. 6. None of these patients had received previous chemotherapy or radiation.
All participants had measurable disease by RECIST v. 1.0 criteria. Both CT and PET scans were performed at Time 0 , Time 1 and Time 2. Radiographic responses were quantified by the percentage of changes in the sum of all greatest tumor diameters between post- and pre-treatment scans. Institutional radiologists 
evaluated all scans. OS was defined as the interval between the date of treatment and the date of death. PFS was defined as the interval between the date of treatment and the date of progression or death from any cause. Participants without an event were censored as of the date of last follow-up, which occurred between August and September 2009.

All procedures were approved by the Institution Review Board (IRB) from the University of South Florida (FWA00001669) and were in accordance with the Helsinki Declaration of 1975. Participants prospectively provided informed consent for the use of their tissue in research.

Measurement of plasma markers. Heparinized blood samples were drawn and centrifuged at $800 \mathrm{~g}$ for $10 \mathrm{~min}$ to extract plasma and then stored at $-80^{\circ} \mathrm{C}$. HPLC/MS/MS was performed with gradient elution on a C18 column (Thermo Betabasic, $150 \mathrm{~mm} \times 2.1 \mathrm{~mm}, 5 \mu \mathrm{m}$ particles) with matching guard column at a flow rate of $500 \mu \mathrm{L} / \mathrm{min}$ using heated electrospray ionization in the positive ion mode.$^{50}$ Gradient solvents were $0.1 \%$ formic acid in water and acetonitrile with $0.1 \%$ formic acid (HPLC grade, Fisher-Scientific). The mass spectrometer (TSQ Quantum Ultra, Thermo) was operated in selected reaction monitoring mode (SRM). Calibration standards for Trp and Kyn (Fisher-Scientific) were prepared in albumin (Sigma) in the ranges of $10-2,000 \mathrm{ng} / \mathrm{mL}$ for Kyn and $100-20,000 \mathrm{ng} / \mathrm{mL}$ for Trp. Quality control samples were prepared in albumin at 10 , $100,1000 \mathrm{ng} / \mathrm{mL}$ for Kyn and 100, 1,000, 10,000 ng/mL for Trp. $150 \mu \mathrm{L}$ of internal standard solution containing Trp-d 3 at 4,000 ng/mL and Kyn-d6 at $400 \mathrm{ng} / \mathrm{mL}$ (Cambridge Isotopes) were added and mixed to $150 \mu \mathrm{L}$ of calibration standard, quality control, and clinical specimens. For protein precipitation, $30 \mu \mathrm{L}$ of $2.4 \mathrm{M}$ perchloric acid (Fisher-Scientific) were added, samples were vortexed and cooled for $5 \mathrm{~min}$, then centrifuged at 20,400 $\mathrm{g}$ for $20 \mathrm{~min}$. The supernatant was transferred to a filter tube $(0.44 \mu \mathrm{m})$ and re-centrifuged. The filtered sample was transferred to a glass vial with $400 \mu \mathrm{L}$ insert and $10 \mu \mathrm{L}$ was injected onto the column. Each sample was performed in triplicate, and individual mean concentrations were recorded. The intraassay and day-to-day analytic coefficients of variation were less than $5 \%$ for each analyte (Table S1).

Statistics. The plasma concentrations of Kyn and Trp, as well as Kyn/Trp ratios approximated a parametric distribution. Therefore, data were presented as means $\pm \mathrm{SD}$. Due to the small sample size, the associations between serum biomarker levels and clinicopathologic variables were evaluated with Wilcoxon ranksum and Kruskal-Wallis tests. Wilcoxon signed rank was used to compare between time points. Correlation was estimated using Spearman's rho. Survival curves were calculated according to the Kaplan-Meier method. To address the experimental hypothesis, the statistical population was equally divided into "hig" and "low" patients using the median Kyn/Trp value as pre-specified cut-point. The effects of biomarkers on PFS and OS were evaluated using log-rank (Mantel-Cox) test and Cox proportionalhazards regression models. All tests performed were two-tailed. Statistical analysis was performed using the SAS software (version 8.0). Figures and survival plots were generated using GraphPad Prism $^{\circledR}$ (version 5.04).

\section{Disclosure of Potential Conflicts of Interest}

The authors have no conflicts of interest to disclose.

\section{Acknowledgments}

This work was funded by NCI R01-CA102726 and P50-CA119997, and supported in part by the NIH/NCATS Clinical and Translational Science Award to the University of Florida UL1 TR000064. The content is solely the responsibility of the authors and does not necessarily represent the official views of the National Cancer Institute or the National Institutes of Health.

\section{Supplemental Material}

Supplemental materials may be found here:

http://www.landesbioscience.com/journals/oncoimmunology/ article/23428/

\section{References}

1. Lee GK, Park HJ, Macleod M, Chandler P, Munn DH, Mellor AL. Tryptophan deprivation sensitizes activated $\mathrm{T}$ cells to apoptosis prior to cell division. Immunology 2002; 107:452-60; PMID:12460190; http://dx.doi. org/10.1046/j.1365-2567.2002.01526.x.

2. Munn DH, Sharma MD, Baban B, Harding HP, Zhang Y, Ron D, et al. GCN2 kinase in T cells mediates proliferative arrest and anergy induction in response to indoleamine 2,3-dioxygenase. Immunity 2005; 22:633-42; PMID:15894280; http://dx.doi. org/10.1016/j.immuni.2005.03.013.

3. Friberg M, Jennings R, Alsarraj M, Dessureault S, Cantor A, Extermann M, et al. Indoleamine 2,3-dioxygenase contributes to tumor cell evasion of $\mathrm{T}$ cellmediated rejection. Int J Cancer 2002; 101:1515; PMID:12209992; http://dx.doi.org/10.1002/ ijc. 10645 .

4. Munn DH, Sharma MD, Hou D, Baban B, Lee JR, Antonia SJ, et al. Expression of indoleamine 2,3-dioxygenase by plasmacytoid dendritic cells in tumordraining lymph nodes. J Clin Invest 2004; 114:280-90; PMID:15254595.
5. Brenk M, Scheler M, Koch S, Neumann J, Takikawa $\mathrm{O}$, Häcker G, et al. Tryptophan deprivation induces inhibitory receptors ILT3 and ILT4 on dendritic cells favoring the induction of human CD4+CD25+ Foxp3+ T regulatory cells. J Immunol 2009; 183:14554; PMID:19535644; http://dx.doi.org/10.4049/jimmunol.0803277.

6. Terness P, Bauer TM, Röse L, Dufter C, Watzlik A, Simon $\mathrm{H}$, et al. Inhibition of allogeneic $\mathrm{T}$ cell proliferation by indoleamine 2,3-dioxygenase-expressing dendritic cells: mediation of suppression by tryptophan metabolites. J Exp Med 2002; 196:44757; PMID:12186837; http://dx.doi.org/10.1084/ jem.20020052.

7. Frumento G, Rotondo R, Tonetti M, Damonte G, Benatti U, Ferrara GB. Tryptophan-derived catabolites are responsible for inhibition of $\mathrm{T}$ and natural killer cell proliferation induced by indoleamine 2,3-dioxygenase. J Exp Med 2002; 196:459-68; PMID:12186838; http://dx.doi.org/10.1084/jem.20020121.
8. Metz R, Rust S, Duhadaway JB, Mautino MR, Munn $\mathrm{DH}$, Vahanian NN, et al. IDO inhibits a tryptophan sufficiency signal that stimulates mTOR: A novel IDO effector pathway targeted by D-1-methyl-tryptophan. OncoImmunology 2012; 1:1460-8; PMID:23264892; http://dx.doi.org/10.4161/onci.21716.

9. Uyttenhove C, Pilotte L, Théate I, Stroobant V, Colau D, Parmentier N, et al. Evidence for a tumoral immune resistance mechanism based on tryptophan degradation by indoleamine 2,3-dioxygenase. Nat Med 2003; 9:1269-74; PMID:14502282; http://dx.doi. org/10.1038/nm934.

10. Zamanakou M, Germenis AE, Karanikas V. Tumor immune escape mediated by indoleamine 2,3-dioxygenase. Immunol Lett 2007; 111:69-75; PMID:17644189; http://dx.doi.org/10.1016/j.imlet.2007.06.001.

11. Ou X, Cai S, Liu P, Zeng J, He Y, Wu X, et al Enhancement of dendritic cell-tumor fusion vaccine potency by indoleamine-pyrrole 2,3-dioxygenase inhibitor, 1-MT. J Cancer Res Clin Oncol 2008; 134:52533; PMID:17909857; http://dx.doi.org/10.1007/ s00432-007-0315-9. 
12. Wobser M, Voigt H, Houben R, Eggert AO, Freiwald $M$, Kaemmerer U, et al. Dendritic cell based antitumor vaccination: impact of functional indoleamine 2,3-dioxygenase expression. Cancer Immunol Immunother 2007; 56:1017-24; PMID:17195079; http://dx.doi.org/10.1007/s00262-006-0256-1.

13. Muller AJ, DuHadaway JB, Donover PS, Sutanto-Ward E, Prendergast GC. Inhibition of indoleamine 2,3-dioxygenase, an immunoregulatory target of the cancer suppression gene Bin1, potentiates cancer chemotherapy. Nat Med 2005; 11:312-9; PMID:15711557; http:// dx.doi.org/10.1038/nm1196.

14. Karanikas V, Zamanakou M, Kerenidi T, Dahabreh J, Hevas A, Nakou M, et al. Indoleamine 2,3-dioxygenase (IDO) expression in lung cancer. Cancer Biol Ther 2007; 6:1258-62; PMID:17700060.

15. Jemal A, Siegel R, Xu J, Ward E. Cancer statistics, 2010. CA Cancer J Clin 2010; 60:277-300; PMID:20610543; http://dx.doi.org/10.3322/ caac. 20073.

16. SEER http://www.seer.cancer.gov 2000 - 2007.

17. Kim AW, Johnson KM, Detterbeck FC. The lung cancer stage page: there when you need it--staginglungcancer.org. Chest 2012; 141:581-6; PMID:22396557; http://dx.doi.org/10.1378/chest.11-3192.

18. Farjah F, Wood DE, Yanez D $3^{\text {rd }}$, Symons RG, Krishnadasan B, Flum DR. Temporal trends in the management of potentially resectable lung cancer. Ann Thorac Surg 2008; 85:1850-5, discussion 1856; PMID:18498783; http://dx.doi.org/10.1016/j.athoracsur.2007.12.081.

19. Curran W, Scott C, Langer C, Komaki R, Lee JS, Hauser $\mathrm{S}$, et al. Long-term benefit is observed in a phase III comparison of sequential vs concurrent chemo-radiation for patients with unresected stage III non small cell lung cancer: RTOG 9410 [abstract]. Proc Am Soc Clin Oncol 2003; 22:621a.

20. Rusch V, Klimstra D, Venkatraman E, Oliver J, Martini $\mathrm{N}$, Gralla R, et al. Aberrant p53 expression predicts clinical resistance to cisplatin-based chemotherapy in locally advanced non-small cell lung cancer. Cancer Res 1995; 55:5038-42; PMID:7585548.

21. Kandioler-Eckersberger D, Kappel S, Mittlböck M, Dekan G, Ludwig C, Janschek E, et al. The TP53 genotype but not immunohistochemical result is predictive of response to cisplatin-based neoadjuvant therapy in stage III non-small cell lung cancer. J Thorac Cardiovasc Surg 1999; 117:744-50; PMID:10096970; http://dx.doi.org/10.1016/S0022-5223(99)70295-3.

22. Pagès F, Galon J, Dieu-Nosjean MC, Tartour E, Sautès-Fridman C, Fridman WH. Immune infiltration in human tumors: a prognostic factor that should not be ignored. Oncogene 2010; 29:1093102; PMID:19946335; http://dx.doi.org/10.1038/ onc.2009.416.

23. Spierings DCJ, de Vries EGE, Timens W, Groen HJM, Boezen HM, de Jong S. Expression of TRAIL and TRAIL death receptors in stage III non-small cell lung cancer tumors. Clin Cancer Res 2003; 9:3397-405; PMID:12960128.

24. Suzuki Y, Suda T, Furuhashi K, Suzuki M, Fujie $\mathrm{M}$, Hahimoto D, et al. Increased serum kynurenine/tryptophan ratio correlates with disease progression in lung cancer. Lung Cancer 2010; 67:361-5; PMID:19487045; http://dx.doi.org/10.1016/j.lungcan.2009.05.001.

25. Engin AB, Ozkan Y, Fuchs D, Yardim-Akaydin S. Increased tryptophan degradation in patients with bronchus carcinoma. Eur J Cancer Care (Engl) 2010; 19:803-8; PMID:19702697; http://dx.doi. org/10.1111/j.1365-2354.2009.01122.x.

26. Chang MY, Boulden J, Katz JB, Wang L, Meyer TJ, Soler AP, et al. Bin1 ablation increases susceptibility to cancer during aging, particularly lung cancer. Cancer Res 2007; 67:7605-12; PMID:17699764; http:// dx.doi.org/10.1158/0008-5472.CAN-07-1100.
27. Ratto GB, Zino P, Mirabelli S, Minuti P, Aquilina R, Fantino G, et al. A randomized trial of adoptive immunotherapy with tumor-infiltrating lymphocytes and interleukin-2 versus standard therapy in the postoperative treatment of resected nonsmall cell lung carcinoma. Cancer 1996; 78:244 51; PMID:8673999; http://dx.doi.org/10.1002/ (SICI) 1097-0 142(19960715)78:2<244::AID CNCR9>3.0.CO;2-L.

28. Astigiano S, Morandi B, Costa R, Mastracci L, D'Agostino A, Ratto GB, et al. Eosinophil granulocytes account for indoleamine 2,3-dioxygenase-mediated immune escape in human non-small cell lung cancer Neoplasia 2005; 7:390-6; PMID:15967116; http:// dx.doi.org/10.1593/neo.04658.

29. de Jong RA, Nijman HW, Boezen HM, Volmer M, Ten Hoor KA, Krijnen J, et al. Serum tryptophan and kynurenine concentrations as parameters for indoleamine 2,3-dioxygenase activity in patients with endometrial, ovarian, and vulvar cancer. Int J Gynecol Cancer 2011; 21:1320-7; PMID:21720257.

30. Feder-Mengus C, Wyler S, Hudolin T, Ruszat R, Bubendorf L, Chiarugi A, et al. High expression of indoleamine 2,3-dioxygenase gene in prostate cancer Eur J Cancer 2008; 44:2266-75; PMID:18619832; http://dx.doi.org/10.1016/j.ejca.2008.05.023.

31. Xie Q, Wang L, Zhu B, Wang Y, Gu J, Chen Z. The expression and significance of indoleamine -2,3 -dioxygenase in non-small cell lung cancer cell. Zhongguo Fei Ai Za Zhi 2008; 11:115-9; PMID:20727279.

32. Weinlich G, Murr C, Richardsen L, Winkler C, Fuchs D. Decreased serum tryptophan concentration predicts poor prognosis in malignant melanoma patients. Dermatology 2007; 214:8-14; PMID:17191041; http://dx.doi.org/10.1159/000096906.

33. Cavia-Saiz M, Muñiz P, De Santiago R, HerrerosVillanueva M, Garcia-Giron C, Lopez AS, et al. Changes in the levels of thioredoxin and indoleamine2,3-dioxygenase activity in plasma of patients with colorectal cancer treated with chemotherapy. Biochem Cell Biol 2012; 90:173-8; PMID:22257103; http:// dx.doi.org/10.1139/o11-077.

34. Liu J, Lu G, Tang F, Liu Y, Cui G. Localization of indoleamine 2,3-dioxygenase in human esophageal squamous cell carcinomas. Virchows Arch 2009; 455:441-8; PMID:19844741; http://dx.doi. org/10.1007/s00428-009-0846-3.

35. Sakurai K, Enomoto K, Amano S, Kimura T, Sugito K, Kimizuka K, et al. Study of indoleamine 2,3-dioxygenase expression in patients of esophageal squamous cell carcinoma. Gan To Kagaku Ryoho 2004; 31:1780-2; PMID:15553713.

36. Sakurai K, Fujisaki S, Nagashima S, Shibata M, Maeda T, Ueda Y, et al. Study of indoleamine 2,3-dioxygenase expression in patients of thyroid cancer. Gan To Kagaku Ryoho 2011; 38:1927-9; PMID:22202241.

37. Chamuleau MED, van de Loosdrecht AA, Hess CJ, Janssen JJWM, Zevenbergen A, Delwel R, et al. High INDO (indoleamine 2,3-dioxygenase) mRNA level in blasts of acute myeloid leukemic patients predicts poor clinical outcome. Haematologica 2008; 93:1894-8; PMID:19050070; http://dx.doi.org/10.3324/haematol.13112.

38. Lyon DE, Walter JM, Starkweather AR, Schubert CM, McCain NL. Tryptophan degradation in women with breast cancer: a pilot study. BMC Res Notes 2011; 4:156; PMID:21615916; http://dx.doi. org/10.1186/1756-0500-4-156.

39. Juhász $\mathrm{C}$, Muzik $\mathrm{O}$, Lu X, Jahania MS, Soubani AO, Khalaf M, et al. Quantification of tryptophan transport and metabolism in lung tumors using PET. J Nucl Med 2009; 50:356-63; PMID:19223408; http:// dx.doi.org/10.2967/jnumed.108.058776.

40. Okamoto A, Nikaido T, Ochiai K, Takakura S, Saito $\mathrm{M}$, Aoki $\mathrm{Y}$, et al. Indoleamine 2,3-dioxygenase serves as a marker of poor prognosis in gene expression profiles of serous ovarian cancer cells. Clin Cancer Res 2005; 11:6030-9; PMID:16115948; http://dx.doi. org/10.1158/1078-0432.CCR-04-2671.
41. Sim SH, Ahn YO, Yoon J, Kim TM, Lee SH, Kim DW, et al. Influence of chemotherapy on nitric oxide synthase, indole-amine-2,3-dioxygenase and CD124 expression in granulocytes and monocytes of nonsmall cell lung cancer. Cancer Sci 2012; 103:155-60; PMID:22107611; http://dx.doi.org/10.1111/j.13497006.2011.02158.x.

42. Ribas A, Comin-Anduix B, Economou JS, Donahue TR, de la Rocha P, Morris LF, et al. Intratumoral immune cell infiltrates, FoxP3, and indoleamine 2,3-dioxygenase in patients with melanoma undergoing CTLA4 blockade. Clin Cancer Res 2009; 15:390-9; PMID:19118070; http://dx.doi.org/10.1158/10780432.CCR-08-0783.

43. de Jong WHA, Smit R, Bakker SJL, de Vries EGE Kema IP. Plasma tryptophan, kynurenine and 3-hydroxykynurenine measurement using automated on-line solid-phase extraction HPLC-tandem mass spectrometry. J Chromatogr B Analyt Technol Biomed Life Sci 2009; 877:603-9; PMID:19196554; http:// dx.doi.org/10.1016/j.jchromb.2009.01.015.

44. de Jong WHA, Smit R, Bakker SJL, de Vries EGE, Kema IP. Plasma tryptophan, kynurenine and 3-hydroxykynurenine measurement using automated on-line solid-phase extraction HPLC-tandem mass spectrometry. J Chromatogr B Analyt Technol Biomed Life Sci 2009; 877:603-9; PMID:19196554; http:// dx.doi.org/10.1016/j.jchromb.2009.01.015.

45. Vincent J, Mignot G, Chalmin F, Ladoire S, Bruchard $\mathrm{M}$, Chevriaux A, et al. 5-Fluorouracil selectively kills tumor-associated myeloid-derived suppressor cells resulting in enhanced $\mathrm{T}$ cell-dependent antitumor immunity. Cancer Res 2010; 70:3052-61; PMID:20388795; http://dx.doi.org/10.1158/00085472.CAN-09-3690.

46. Meniawy TM, Nowak AK, Lake RA. Effect of Chemotherapy on the Tumor Microenvironment and Anti-tumor Immunity. Tumor Ablation 2013; 5:1-28; http://dx.doi.org/10.1007/978-94-007-4694-7_1.

47. Hsu J. Multiple comparisons: theory and methods London: Chapman \& Hall/CRC, 1996.

48. Soliman HH, Neuger A, Noyes D, Vahanian NN, Link CJ, Munn D, et al. A phase I study of 1-methylD-tryptophan in patients with advanced malignancies [supplement]. J Clin Oncol 2012; 30:abstr2501.

49. Bepler G, Dilling TJ, Wagner H, Hazelton T, Williams C, Chen DT, et al. Phase II trial of induction gemcitabine and carboplatin followed by conformal thoracic radiation to 74 Gy with weekly paclitaxel and carboplatin in unresectable stage III non-small cell lung cancer. J Thorac Oncol 2011; 6:553-8; PMID:21289520; http://dx.doi.org/10.1097/JTO.0b013e31820b8d88.

50. Dharnidharka VR, Gupta S, Al Khasawneh E, Haafiz A, Shuster JJ, Theriaque DW, et al. Immune biomarker panel monitoring utilizing IDO enzyme activity and CD4 ATP levels: prediction of acute rejection vs. viral replication events. Pediatr Transplant 2011; 15:321-8; PMID:21492353; http://dx.doi.org/10.1111/j.1399 3046.2011.01485.x

51. Inaba T, Ino K, Kajiyama H, Yamamoto E, Shibata K, Nawa A, et al. Role of the immunosuppressive enzyme indoleamine 2,3-dioxygenase in the progression of ovarian carcinoma. Gynecol Oncol 2009; 115:18592; PMID:19665763; http://dx.doi.org/10.1016/j. ygyno.2009.07.015.

52. Riesenberg R, Weiler C, Spring O, Eder M, Buchner A, Popp T, et al. Expression of indoleamine 2,3-dioxygenase in tumor endothelial cells correlates with long-term survival of patients with renal cell carcinoma. Clin Cancer Res 2007; 13:6993-7002; PMID:18056175; http://dx.doi.org/10.1158/1078-0432.CCR-07-0942.

53. Pan K, Wang $\mathrm{H}$, Chen MS, Zhang HK, Weng DS, Zhou J, et al. Expression and prognosis role of indoleamine 2,3-dioxygenase in hepatocellular carcinoma. J Cancer Res Clin Oncol 2008; 134:1247-53; PMID:18438685; http://dx.doi.org/10.1007/s00432008-0395-1. 
54. Takao M, Okamoto A, Nikaido T, Urashima M, Takakura S, Saito $\mathrm{M}$, et al. Increased synthesis of indoleamine-2,3-dioxygenase protein is positively associated with impaired survival in patients with seroustype, but not with other types of, ovarian cancer. Oncol Rep 2007; 17:1333-9; PMID:17487387.

55. Jacquemier J, Bertucci F, Finetti P, Esterni B, CharafeJauffret E, Thibult ML, et al. High expression of indoleamine 2,3-dioxygenase in the tumour is associated with medullary features and favourable outcome in basal-like breast carcinoma. Int J Cancer 2012; 130:96104; PMID:21328335; http://dx.doi.org/10.1002/ ijc. 25979.

56. Laimer K, Troester B, Kloss F, Schafer G, Obrist P, Perathoner A, et al. Expression and prognostic impact of indoleamine 2,3-dioxygenase in oral squamous cell carcinomas. Oral Oncol 2011; 47:3527; PMID:21440489; http://dx.doi.org/10.1016/j. oraloncology.2011.03.007.

57. Sakurai K, Amano S, Enomoto K, Kashio M, Saito Y, Sakamoto A, et al. Study of indoleamine 2,3-dioxygenase expression in patients with breast cancer. Gan To Kagaku Ryoho 2005; 32:1546-9; PMID:16315864.

58. Brandacher G, Perathoner A, Ladurner R, Schneeberger $\mathrm{S}$, Obrist $\mathrm{P}$, Winkler $\mathrm{C}$, et al. Prognostic value of indoleamine 2,3-dioxygenase expression in colorectal cancer: effect on tumor-infiltrating T cells. Clin Cancer Res 2006; 12:1144-51; PMID:16489067; http://dx.doi. org/10.1158/1078-0432.CCR-05-1966.

59. Ferdinande L, Decaestecker C, Verset L, Mathieu A, Moles Lopez X, Negulescu AM, et al. Clinicopathological significance of indoleamine 2,3-dioxygenase 1 expression in colorectal cancer. $\mathrm{B}$ J Cancer 2012; 106:141-7; PMID:22108515; http:// dx.doi.org/10.1038/bjc.2011.513.

60. Ino K, Yoshida N, Kajiyama H, Shibata K, Yamamoto E, Kidokoro K, et al. Indoleamine 2,3-dioxygenase is a novel prognostic indicator for endometrial cancer. $\mathrm{Br} J$ Cancer 2006; 95:1555-61; PMID:17117179; http:// dx.doi.org/10.1038/sj.bjc.6603477.

61. Witkiewicz A, Williams TK, Cozzitorto J, Durkan B, Showalter SL, Yeo CJ, et al. Expression of indoleamine 2,3-dioxygenase in metastatic pancreatic ductal adenocarcinoma recruits regulatory $\mathrm{T}$ cells to avoid immune detection. J Am Coll Surg 2008; 206:84954, discussion 854-6; PMID:18471709; http://dx.doi. org/10.1016/j.jamcollsurg.2007.12.014.

62. Cavia-Saiz M, Muñiz P, De Santiago R, HerrerosVillanueva M, Garcia-Giron C, Lopez AS, et al. Changes in the levels of thioredoxin and indoleamine2,3-dioxygenase activity in plasma of patients with colorectal cancer treated with chemotherapy. Biochem Cell Biol 2012; 90:173-8; PMID:22257103; http:// dx.doi.org/10.1139/o11-077.
63. Urakawa H, Nishida Y, Nakashima H, Shimoyama Y, Nakamura S, Ishiguro N. Prognostic value of indoleamine 2,3-dioxygenase expression in high grade osteosarcoma. Clin Exp Metastasis 2009; 26:1005-12; PMID:19802733; http://dx.doi.org/10.1007/s10585009-9290-7.

64. Chen PW, Mellon JK, Mayhew E, Wang S, He YG, Hogan N, et al. Uveal melanoma expression of indoleamine 2,3-deoxygenase: establishment of an immune privileged environment by tryptophan depletion. Exp Eye Res 2007; 85:617-25; PMID:17870068; http:// dx.doi.org/10.1016/j.exer.2007.07.014.

65. Kobayashi N, Kubota K, Kato S, Watanabe S, Shimamura T, Kirikoshi H, et al. FOXP3+ regulatory T cells and tumoral indoleamine 2,3-dioxygenase expression predicts the carcinogenesis of intraductal papillary mucinous neoplasms of the pancreas. Pancreatology 2010; 10:631-40; PMID:21051918; http://dx.doi. org/10.1159/000308966.

66. de Jong RA, Kema IP, Boerma A, Boezen HM, der Want JJ, Gooden MJM, et al. Prognostic role of indoleamine 2,3-dioxygenase in endometrial carcinoma. Gynecol Oncol 2012; 126:474-80; PMID:22668882; http://dx.doi.org/10.1016/j.ygyno.2012.05.034

67. de Jong RA, Toppen NL, Ten Hoor KA, Boezen HM, Kema IP, Hollema H, et al. Status of cellular immunity lacks prognostic significance in vulvar squamous carcinoma. Gynecol Oncol 2012; 125:186 93; PMID:22155674; http://dx.doi.org/10.1016/j. ygyno.2011.12.416.

68. Brody JR, Costantino CL, Berger AC, Sato T, Lisanti MP, Yeo CJ, et al. Expression of indoleamine 2,3-dioxygenase in metastatic malignant melanoma recruits regulatory $\mathrm{T}$ cells to avoid immune detection and affect survival. Cell Cycle 2009; 8:1930-4; PMID:19448397; http://dx.doi.org/10.4161/cc.8.12.8745.

69. Lee JR, Dalton RR, Messina JL, Sharma MD, Smith DM, Burgess RE, et al. Pattern of recruitment of immunoregulatory antigen-presenting cells in malignant melanoma. Lab Invest 2003; 83:145766; PMID:14563947; http://dx.doi.org/10.1097/01. LAB.0000090158.68852.D1

70. Nakamura T, Shima T, Saeki A, Hidaka T, Nakashima A, Takikawa O, et al. Expression of indoleamine 2, 3-dioxygenase and the recruitment of Foxp3-expressing regulatory $\mathrm{T}$ cells in the development and progression of uterine cervical cancer. Cancer Sci 2007; 98:874-81; PMID:17433037; http://dx.doi.org/10.1111/j.13497006.2007.00470.x
71. Ishio T, Goto S, Tahara K, Tone S, Kawano K, Kitano $\mathrm{S}$. Immunoactivative role of indoleamine 2,3-dioxygenase in human hepatocellular carcinoma. J Gastroenterol Hepatol 2004; 19:319-26; PMID:14748880; http:// dx.doi.org/10.1111/j.1440-1746.2003.03259.x.

72. Gao YF, Peng RQ, Li J, Ding Y, Zhang X, Wu $\mathrm{XJ}$, et al. The paradoxical patterns of expression of indoleamine 2,3-dioxygenase in colon cancer. J Transl Med 2009; 7:71; PMID:19695096; http://dx.doi. org/10.1186/1479-5876-7-71.

73. Ninomiya S, Hara T, Tsurumi H, Hoshi M, Kanemura $\mathrm{N}$, Goto $\mathrm{N}$, et al. Indoleamine 2,3-dioxygenase in tumor tissue indicates prognosis in patients with diffuse large B-cell lymphoma treated with R-CHOP. Ann Hematol 2011; 90:409-16; PMID:20938662; http:// dx.doi.org/10.1007/s00277-010-1093-z.

74. Ino K, Yamamoto E, Shibata K, Kajiyama H, Yoshida $\mathrm{N}$, Terauchi $\mathrm{M}$, et al. Inverse correlation between tumoral indoleamine 2,3-dioxygenase expression and tumor-infiltrating lymphocytes in endometrial cancer: its association with disease progression and survival. Clin Cancer Res 2008; 14:2310-7; PMID:18413819; http://dx.doi.org/10.1158/1078-0432.CCR-07-4144.

75. Inaba T, Ino K, Kajiyama H, Shibata K, Yamamoto E, Kondo S, et al. Indoleamine 2,3-dioxygenase expression predicts impaired survival of invasive cervical cancer patients treated with radical hysterectomy. Gynecol Oncol 2010; 117:423-8; PMID:20350764; http:// dx.doi.org/10.1016/j.ygyno.2010.02.028.

76. Speeckaert R, Vermaelen K, van Geel N, Autier $\mathrm{P}$, Lambert J, Haspeslagh $\mathrm{M}$, et al. Indoleamine 2,3-dioxygenase, a new prognostic marker in sentinel lymph nodes of melanoma patients. Eur J Cancer 2012; 48:2004-11; PMID:22033321; http://dx.doi. org/10.1016/j.ejca.2011.09.007. 